\title{
Una perspectiva histórico-social sobre las relaciones entre el Estado y el campesinado en la República Dominicana*
}

\author{
Pedro L. San Miguel \\ UNIVERSIDAD DE PUERTO RICO
}

Se intentaran trazar las etapas históricas en las relaciones entre Estado y campesinado en República Dominicana.

Se identifican primero los factores que contribuyeron a la formación del campesinado en la colonia y el siglo XIX. Luego se destacan los momentos cruciales en el proceso de "domesticación" del campesinado. Finalmente, se sugieren los factores que han incidido sobre esas relaciones en las últimas décadas, acentuando la "política del abandono" de las masas rurales que ha conllevado la modernización económica.

LA FORMACIÓN DEL CAMPESINADO: UNA MIRADA DE "LARGA DURACIÓN"

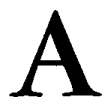
diferencia de otras sociedades caribeñas, en la República Dominicana (conocida como Santo Domingo durante el periodo colonial) no existió una economía de plan-

\footnotetext{
* Este artículo forma parte de un libro en preparación (El pasado relegado: Ensayos sobre la bistoria agraria de la República Dominicana), y sintetiza aspectos de trabajos que he escrito anteriormente sobre el campesinado. Por to tanto, he limitado las referencias a un mínimo.
}

tación que impidiese el surgimiento y la existencia del campesinado. ${ }^{1}$ En el siglo XVI se desarrolló una economía de exportación basada en la producción de azúcar, sin embargo, dicha economía entró en decadencia para fines de esa centuria. Durante los siglos XVII y XVIII, la economía dominicana giró en torno a la agricultura de subsistencia y de la ganadería de hato. Con una escasa población y vínculos extremadamente débiles con los

${ }^{1}$ Clausner, Rural, 1973; San Miguel, "Making", 1990, pp. 143-162, y Campesinos, 1997, pp. 17-48. 
mercados europeos, Santo Domingo contó en ese entonces con una estructura agraria relativamente "abierta", en la cual, los recursos económicos no estaban tan concentrados como en las sociedades de plantación del Caribe. Fue en este contexto en el que surgió el campesinado. Dedicado a la agricultura de subsistencia y -en algunas regiones del país- al cultivo en pequeña escala de productos comerciales, tales como el tabaco, el campesinado contó con un amplio acceso a la tierra. Por otro lado, el Estado tuvo pocas interferencias en la vida de los campesinos. Combinando la agricultura con la caza y un comercio de poca envergadura, las masas rurales de Santo Domingo conformaron lo que Raymundo González ha denominado un "campesinado arcaico", cuyos niveles de integración con el mercado y con el Estado eran su mamente precarios. ${ }^{2}$

La situación de este campesinado cambió poco hasta el siglo XIX, cuando hubo varios intentos por encuadrar a las masas campesinas en los esquemas de dominación estatal. Durante el periodo conocido como la "Dominación Haitiana" (1822-1844), en que la recién creada República de Haití extendió su poder hasta la antigua colonia española de Santo Domingo, se intentó alterar el régimen de tierras y, en consecuencia, cambiar las bases de la sociedad rural. Entre otras cosas, los gobernantes haitianos trataron de fomentar la agricultura comercial a costa de la ganadería.

\footnotetext{
²González, "Campesinos", 1992, pp. 15-28.
}

Ello provocó el descontento entre los sectores vinculados tradicionalmente a la ganadería, por lo que los ocupantes optaron por abandonar tales proyectos. Con todo, las políticas agrarias del régimen haitiano contribuyeron al fortalecimiento del campesinado; la abolición de la esclavitud y el reparto de tierras entre los libertos y los campesinos sin tierra son los principales indicadores sociales de tal proceso. Además, la relativa estabilidad política que vivió Santo Domingo bajo la dominación haitiana, contribuyó a la expansión de las actividades económicas propias del campesinado. Por ejemplo, entre 1822 y 1844 , las exportaciones de tabaco aumentaron significativamente, además de estabilizarse la venta de la hoja a los comerciantes europeos, mayormente alemanes, que se acercaron a las costas de la isla la Española con el fin de obtener este producto. ${ }^{3}$

Sin embargo, en la "larga duración", quizá el efecto más significativo de la dominación haitiana, secuela de la revolución de esclavos en la antigua colonia de Saint Domingue a fines del siglo XVII, fue el "bloqueo histórico" que supuso al surgimiento de una economía de plantación en Santo Domingo. La política antiesclavista del Estado haitiano a partir de su fundación en 1804, junto a las consecuencias de la revolución antiesclavista y

\footnotetext{
${ }^{3}$ Machín, "Orígenes", 1973, pp. 19-34; Moya Pons, Dominación, 1978; Marte, Estadísticas, 1984. Sobre la importancia del tabaco en la formación del campesinado dominicano, ver: Lluberes, "Tabaco", 1977, pp. 13-26; "Economía", 1973, pp. 35-60, y "Crisis", 1984, pp. 3-22.
} 
anticolonial sobre la estructura económica y social de ambos países, tuvo por resultado el debilitamiento del sistema de plantación en la isla La Española. Aunque resucitado en algunas regiones de Haití en ciertos periodos históricos -por ejemplo, en el norte del país, bajo el reinado de Henri Christophe (1807-1820)-, la revolución haitiana y sus secuelas -entre ellas, la ocupación de Santo Domingo de 1822 a 1844-tuvieron como efectos, en Haití, la destrucción del sistema de plantaciones, y, en Santo Domingo, el de retardar su surgimiento hasta fines del siglo XIX. Por el contrario, los sectores campesinos de Haití y de Santo Domingo se vieron fortalecidos como consecuencia del proceso revolucionario iniciado por los esclavos haitianos en la última década del siglo XVII. ${ }^{4}$

Estas condiciones no sufrieron alteraciones fundamentales a lo largo del siglo XIX, a pesar de los cambios políticos que sufrió Santo Domingo. El fin de la dominación haitiana no alteró en lo sustancial la estructura económica y social del país; tampoco resultó afectada durante el breve interludio, de 1861-1865, cuando España volvió a ocupar Santo Domingo. De hecho, hay indicios de que los meros rumores del restablecimiento de la esclavitud en Santo Domingo provocaron la movilización de sectores negros y mulatos contra el régimen español. Hay indicios, igualmente, de que algunas de las medidas del

\footnotetext{
${ }^{4}$ Nicholls, Desaliness, 1979; LundahI, Peasants, 1979.
}

régimen español provocaron el rechazo de sectores del campesinado dominicano; entre ellas hay que mencionar las encaminadas a establecer contribuciones. ${ }^{5}$ Así, durante el siglo XIX el campesinado dominicano expandió sus actividades económicas; en algunas regiones ocupó tierras vírgenes y desarrolló nuevas actividades productivas. En la región del Cibao, económicamente la más importante en el siglo XIX y sede del campesinado más vigoroso, éste se movió hacia el Cibao oriental, donde colonizó tierras de gran fertilidad. Además de tabaco, cultivo tradicional del campesino cibaeño, se extendió el cultivo del cacao y, en las tierras altas, el del café. Este último cultivo también adquirió importancia entre los campesinos de otras regiones, sobre todo en torno a los municipios sureños de Baní y San Cristóbal, donde el café se convirtió en el cultivo comercial por excelencia. ${ }^{6}$

Fue en la década de los setenta del siglo XIX cuando, de manera incipiente, algunas regiones de la República Dominicana comenzaron a sentir los efectos del surgimiento de una economía de plantación. Primero en zonas cercanas a la capital y, luego, en áreas hacia el oeste de la ciuclad de Santo Domingo, en San Pedro de Macorís en el este, y en Puerto Plata en

'Estas son hipótesis que, aunque sugetidas por algunos de los estudios disponibles, no han sido sistemáticamente exploradas por los historiadores.

${ }^{6}$ San Miguel, Campesinos, 1997, pp. 17-94; Bryan, "Producción", 1979, pp. 29-62; Baud, "Transformación", 1986, pp. 17-45. 
la costa norte, se establecieron ingenios que iniciaron la moderna industria del azúcar en esta república. Con la expansión de los cañaverales entre fines del siglo XIX y principios del XX, los campesinos de tales zonas sufrieron una pérdida de sus tierras y,en algunas regiones, pasaron a formar parte de la mano de obra de las plantaciones. No obstante, la producción de azúcar se concentró en regiones muy específicas del país y, por ende, sus efectos estuvieron lejos de sentirse de manera uniforme sobre la totalidad del campesinado dominicano.? Incluso hubo zonas donde los campesinos, forzados a emigrar por la expansión del azúcar, se establecieron en las tierras altas cercanas a los valles cañeros; de ellas bajaban por temporadas a trabajar en las plantaciones o a vender parte de lo que cultivaban en sus parcelas. Así, aunque en ocasiones eran contrapuestos a las plantaciones, los campesinos de tales regiones también se imbricaron a la economía del azúcar a través de la venta de su fuerza de trabajo o de sus productos agrícolas. En consecuencia, a pesar de los cambios sufridos por la economía dominicana entre fines del siglo XIX y principios del $\mathrm{xx}$, el campesinado dominicano estuvo lejos de sufrir un proceso masivo de pérdida de tierras; éste fue, más bien, un fenómeno regional que afectó a los campesinos de zonas muy concretas. En otras regiones, el campesinado continuó desarrollándose tal como lo había hecho anteriormente.

\footnotetext{
${ }^{7}$ Hoetink, Pueblo, 1985, pp. 13-36 y 95-100; Castillo, "Formación", 1984, pp. 23-56.
}

LOS CAMPESINOS Y EL ESTADO

A mediados del siglo XIX, al convertirse en un país independiente, Santo Domingo contaba con un Estado sumamente débil, producto de la falta de integración económica, las ocupaciones extranjeras, los conflictos internos, y la ausencia de comunicaciones que facilitasen el acceso de los organismos estatales a las diversas regiones del país. ${ }^{8}$ En consecuencia, su dominio sobre las masas rurales era muy desigual; dependía de las estructuras de poder a nivel local o de las influencias de los caudillos y caciques regionales, por lo que los gobernantes del país se empeñaban en mantener relaciones clientelistas con ellos. A través de las gobernaciones provinciales y de los organismos municipales, el Estado trataba de ejercer un precario dominio sobre las masas campesinas. Pero el mismo colapsaba periódicamente como resultado de las limitaciones fiscales del Estado $y$ de las frecuentes rebeliones y sublevaciones que afectaron a Santo Domingo hasta principios de este siglo. En no pocas zonas del país, el Estado era una entelequia, inexistente en absoluto. En la frontera con Haití -para mencionar uno de los casos más conocidos- su presencia solía manifestarse en unos cuantos militares que, lejos de validar con sus gestiones la soberanía reclamada en las pomposas declaraciones oficiales, vivían plenamente integrados a un sistema de intercambios económicos, humanos, sociales y

\footnotetext{
${ }^{8}$ Hoetink, Pueblo, 1985; Betances, State, 1995, pp. 9-22.
} 
culturales que expresaban con todo vigor las complejidades típicas de las regiones fronterizas. ${ }^{9}$ En otras regiones, más integradas a las redes comerciales "formales", la presencia del Estado era más evidente; ejercida a través de organismos de alcance local o regional, su dominio mostraba fisuras importantes. Por ello, es inapropiado pensar en la existencia de un poder estatal que ejercía un control estricto sobre la totalidad del territorio y de la población dominicanas; y era, ante todo, sobre las masas campesinas que dicho dominio resultaba más precario y frágil.

Hubo, por supuesto, varias maneras en las que el Estado dejó sentir su presencia sobre la vida de los sectores campesinos. Una de ellas fueron las requisas de bienes, productos agrícolas, animales de carga y transporte que sufrían los campesinos durante las luchas civiles que afectaron al país a fines del siglo XIX. En tales momentos, la sociedad campesina era sometida a fuertes medidas confiscatorias, además de padecer interrupciones en sus tareas productivas tradicionales. Para colmo, las levas forzosas drenaban a la población rural, compelida a marchar detrás de los ejércitos regulares o de los "generales" insurrectos. ${ }^{10}$ Sin embargo, el Estado, a lo largo del siglo XIX, estuvo muy lejos de ejercer una presión constante sobre el

${ }^{9}$ Véase Moya, "Tres", 1992, pp. 17-32; Derby, "Haitians", 1994, pp. 488-526.

${ }^{10}$ La literatura dominicana contiene varias obras en las que se reflejan las consecuencias de las "revoluciones" sobre la población rural. Entre otras, véase: Bosch, Mañosa, 1994. campesinado; ello era un ejemplo más de la relativa debilidad del Estado y de los serios obstáculos que confrontaba para ejercer su dominio sobre el territorio nacional.

Una de las formas en la que el Estado comenzó a ejercer una presión cada vez mayor sobre las masas fue en la regulación de la propiedad de la tierra. Ya he mencionado que, bajo el régimen haitiano de $\mathbf{1 8 2 2 - 1 8 4 4}$, se intentó redefinir el sistema de tierras. Más tarde en ese siglo se volvió a intentar la transformación de la estructura agraria. En particular, se trató de "modernizar" el sistema de tierras eliminando los terrenos comuneros, de origen colonial, y desarrollando un sistema de plena propiedad privada. Estos terrenos eran tierras ocupadas y explotadas por un grupo de propietarios, quienes validaban su dominio con los "pesos de acción" que poseían. Esos "pesos de acción" daban a los condueños la potestad de cultivar cualquier cantidad de tierra en el respectivo terreno comunero y de disponer libremente de las aguas, los pastos y los bosques del mismo, siempre y cuando su uso no interfiriera con el de otros ocupantes. Para buena parte de la elite de fines del siglo pasado, los terrenos comuneros obstaculizaban el surgimiento de una agricultura "moderna" y la inversión de capitales foráneos en la producción agrícola. ${ }^{11}$ Por tal razón, desde fines del siglo XIX se legisló con la

\footnotetext{
"San Miguel, Campesinos, 1997, pp. 189256; Fernández Rodríguez, "Origen", 1980, pp. 4-45; Moreno, "Propiedad", 1980, pp. 47-129.
} 
intención de poner término a este sistema de tenencia de la tierra.

Tales medidas, tuvieron, sin embargo, pocos resultados efectivos; todavía a principios del siglo $\mathrm{xx}$ se hacían esfuerzos para poner fin a la existencia de tal sistema. Entre esas leyes destacó la "Ley sobre división de los terrenos comuneros", de 1911; esta ley y la "Ley de registro de la propiedad territorial", de 1912, constituyeron la punta de lanza del Estado para terminar con las formas tradicionales de posesión y uso de la tierra. ${ }^{12} \mathrm{Y}$, en efecto, a raíz de su aprobación, se evidenció una mayor propensión a dividir dichos terrenos y a registrar las tierras, al igual que a oficializar las transacciones de compraventa, los arrendamientos y las herencias. Ello fue resultado de un doble fenómeno: primero, de las perceptibles presiones que el Estado ejercía, de manera cada vez más eficiente, sobre las masas rurales; $y$, segundo, de la creciente comercialización de la tierra. Esto último fue notable a principios del siglo $\mathrm{XX}$, tanto en aquellas regiones, como el Cibao, que contaban con una larga tradición de economía comercial campesina, como en las zonas donde la agricultura comercial asumió vertientes latifundistas; tal fue el caso del este de la República Dominicana, en torno a los municipios de San Pedro de Macorís y La Romana, sede de las mayores plantaciones azucareras del país.

No contamos con suficientes estudios que muestren los efectos de la

\footnotetext{
${ }^{12}$ González, "Ideología", 1993, pp. 25-43; Baud, Peasants, 1995, pp. 147-173.
}

avanzada de la agricultura comercial y de las medidas estatales sobre los sectores campesinos en las diversas regiones del país. Todavía en sus comienzos, la microhistoria ha realizado poca labor al respecto; a lo sumo, podemos adelantar algunas hipótesis que, espero, puedan ayudar a poner en una perspectiva comparativa tales procesos. Parece, por ejemplo, que en zonas con una agricultura campesina vigorosa, con fuertes vínculos con el mercado y en simbiosis con las clases mercantiles, prevalecía una cultura campesina más alerta a las medidas estatales que ponían en peligro las bases materiales de las masas rurales. Así, la evidencia documental sugiere que en el Cibao, donde existe una tradición basada en el cultivo del tabaco que se remonta al siglo XVIII, el aumento en el registro de las propiedades agrícolas a principios del siglo XX fue también un mecanismo de resistencia del campesinado contra la posibilidad de la desposesión. Ante la comercialización del suelo, los campesinos tuvieron que defender sus tierras frente a la ofensiva latifundista; uno de los medios empleados en su resistencia fue el registro de sus propiedades. De esa manera restaban medios a los latifundistas dispuestos a usar los leguleyismos y la falsificación de títulos para obtener las ticrras ocupadas por los campesinos. Los expedientes del Tribunal de Tierras, de la Conservaduría de Hipotecas y los protocolos notariales de Santiago, corazón de la economía tabacalcra dominicana, muestran a unos campesinos aferrados a las formas tradicionales de posesión del suelo, y resistiendo 
los esfuerzos de los grandes propietarios rurales y de los comerciantes urbanos por subdividir tales tierras de acuerdo con las concepciones "modernas" impulsadas por las medidas estatales. ${ }^{13}$ Por otro lado, aquellas áreas de Santiago donde la desaparición de los terrenos comuneros databa de antiguo, contaban con una numerosa población campesina cuya sola presencia desalentaba la expropiación masiva. Por el contrario, en regionies del país que carecían de una economía campesina similar a la cibaeña, de larga y fuerte tradición mercantil, el proceso de expropiación fue más contundente. En no pocas de estas zonas, su escasa población facilitó el proceso de expropiación del campesinado. En estas áreas, los empresarios "modernos" -sobre todo las corporaciones azucareras- desataron una verdadera política de apropiación de las tierras campesinas. ${ }^{14}$

Santiago, por un lado, y San Pedro de Macorís y La Romana, por otro, representan modelos opuestos sobre las relaciones entre la expansión de la economía de mercado, el Estado y los sectores campesinos. En el primer caso, el de Santiago, el campesinado sobrevivió con pocos rasguños la embestida del Estado y de la economía comercial. En el segundo, los campesinos fueron virtualmente barridos o, a lo sumo, se tuvieron que mover hacia tierras marginales. Seguramente,

${ }^{13}$ San Miguel, Campesinos, 1997, especialmente pp. 189-322.

${ }^{14}$ Knight, Americanos, 1939, pp. 137-52; Alisuquerque, Títulos, 1961; y Calder, Impacto, 1989, pp. 133-68. entre uno y otro modelo encontramos una verdadera gama de posibilidades y alternativas de combinación. Por ejemplo, en áreas remotas, de pobres comunicaciones internas, o de escaso atractivo económico, el campesinado pudo continuar existiendo hasta bien entrado el siglo $\mathrm{xx}$, sin sufrir la expropiación masiva padecida por el de las zonas convertidas en cañaverales. En muchas de estas zonas remotas, la presencia del Estado y de las relaciones comerciales data de los años treinta, cuando el aparato estatal logró extenderse a las más aisladas regiones del país y, aunque con fisuras, alcanzó mayor eficacia en el control de las masas rurales.

Para comprender con toda precisión la instalación del poder estatal en la ruralía dominicana, hay que tener presentes las peculiaridades económicas y sociales regionales, al igual que las relaciones de poder entre los sectores subalternos y los grupos dominantes. La misma diversidad económica del país implicaba que las masas rurales no constituían una masa homogénea..$^{15}$ De hecho, podemos hablar de campesinados -en plural- en la medida en que existían grupos campesinos dedicados a diferentes actividades económicas, con grados de integración al mercado muy variados, y con relaciones diversas con los demás sectores sociales. IIabía, por ejemplo, sectores rurales dedicados a una agricultura itinerante basada en la técnica de la roza, y a la ca-

${ }^{15}$ Solbre las diversidades regionales, véase: Boin y Serulle, Proceso, 1981, vols. I-II. 
cería de reses y cerdos salvajes; los mismos constituían lo que Raymundo González ha denominado "campesino arcaico", 16 remanente de las etapas formativas del campesinado durante el periodo colonial. Carente de vínculos regulares con el mercado, la vida de este "campesino arcaico" transcurría mayormente en el interior de los montes y bosques, donde cazaba y cultivaba. En el siglo XIX, antes de la expansión del cacao hacia la zona, en el Cibao oriental abundaba este tipo de "campesino arcaico", descrito tanto en ensayos de corte sociológico como en la literatura costumbrista. ${ }^{17} \mathrm{Vi}$ da itinerante tenían, también, muchos de los campesinos que, por carecer de tierras, vagaban de un lugar a otro en busca de trabajo. Aunque muchos de ellos seguramente aspiraban a con. seguir una "tierrita", es probable que no todos lo lograban; en otros casos, era innecesario que se convirtiesen en propietarios en el sentido formal del término. Debido a las relaciones que establecían con los propietarios o a las peculiaridades del trabajo que realizaban, a veces podían disfrutar de la tierra ajena como si fuera propia. En los grandes hatos tradicionales, podian criar animales y, en ocasiones, contar con un alto grado de auto. nomía personal. ${ }^{18}$ Eran los campe. sinos que se encontraban en una mejor situación económica, con un acce-

\footnotetext{
${ }^{16}$ González, "Ideología", 1993.

${ }^{17}$ Rodríguez Demorizi, Papeles, 1964; Bonó, Montero, 1968.

${ }^{18}$ Nuevamente, es la literatura la mejor fuente para identificar los diferentes tipos de campesino que se delinean aquí. Véase, sobre todo: Bosch, Camino, 1983. Como he argumentado
}

so más estable al mercado, los que tenían vínculos más regulares con las fuerzas estatales y los sectores dominantes. De nuevo, eran los campesinos cibaeños quienes mejor emblematizan este tipo de campesino. Eran ellos, por otro lado, quienes más sufrían las fluctuaciones del mercado, y las alteraciones de las actividades económicas por las revueltas y "revoluciones" que sufría el país; eran ellos, también, quienes sintieron de forma más directa los intentos del Estado por regular el sistema de tierras y, años después, por imponer nuevas contribuciones.

Independientemente de las palpables diferencias existentes entre los campesinos, para los sectores letrados y dominantes,

el campesinado era un "otro" interno, una "clase peligrosa" sobre la cual el Estado debía ejercer[...] su voluntad "regeneradora" y "civilizadora"; constituía aquel "fragmento de la nación" -aleatorio, imprevisible, inconstante y salvaje, pero necesario en su función productiva- que había que clomeñar si se aspiraba a que el país se integrase al concierto de los países civilizados. ${ }^{19}$

Desde la fundación de la República, en 1844, el campesinado había constituido un sector social de difícil control por los organismos estatales. Por tal razón, desde fines del siglo XIX

en otro lugar, en la obra narrativa de Bosch hay una "intención testimonial, casi de crónica", que hace que sus cuentos de tema rural se aproximen al registro etnográfico (San Miguel, Isla, 1997, especialmente pp. 148-167).

${ }^{19}$ San Miguel, Isla, 1997, p. 149. 


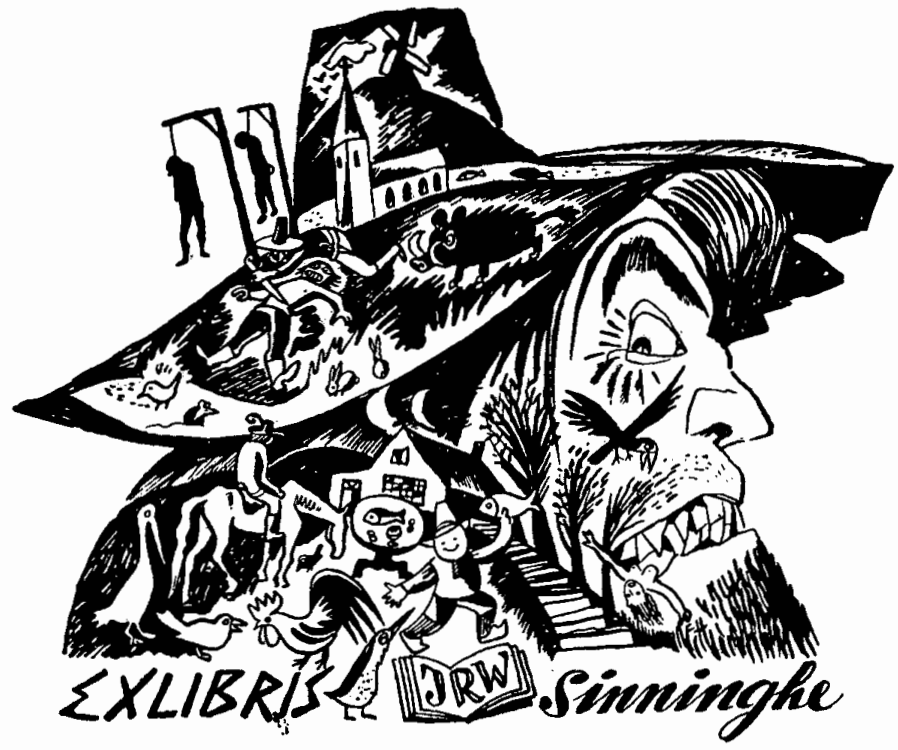

los esfuerzos estatales se encaminaron en buena medida a "domesticar" al campesinado. ${ }^{20}$ Aquí estriba uno de los significados profundos de las leyes agrarias de principios del siglo $\mathrm{XX}$. No empece sus resultados limitados, representaron el intento más abarcador, por parte del Estado, de "domesticar" al campesinado. Para alcanzar un efecto más abarcador, el Estado requería, sin embargo, fortalecerse a sí mismo. Y ello no fue posible sino hasta la ocupación estadunidense de 1916-1924. En estos años, el aparato estatal logró culminar algunos de los esfuerzos que, en tal sentido, se venían realizando desde la dictadura de Ulises Heureaux (1882-1899), y conti-

\footnotetext{
${ }^{20}$ González, "Ideología", 1993; Baud, Peasants, 1995.
}

nuados por los gobiernos de Ramón Cáceres (1906-1911) y Horacio Vázquez (1924-1930). Inspirados en las ideas de "progreso" y "civilización", se propusieron "modernizar" las estructuras económicas y sociales del país; para ello era imprescindible la "modernización" de lo que Hoetink ha llamado los "aparatos de sanción". ${ }^{21}$

LA "DOMESTICACIÓN" DEL CAMPESINADO: INTERVENCIÓN EXTRANJERA Y DICTADURA CRIOLLA

Los problemas financieros del Estado dominicano y el retorno de las gue-

${ }^{21}$ Hoetink, Pueblo, 1985, pp. 133-189. Además: Betances, State, 1995 , pp. 57-93; Brea, Ensayo, 1983; Domínguez, Sociedad, 1994. 
rras civiles luego de la caída de la dictadura de Heureaux, que generaron una verdadera "crisis de gobernabilidad", además de la política estadunidense hacia el Caribe a partir de 1898, llevaron a la ocupación de 1916. El gobierno militar estadunidense tomó una serie de medidas encaminadas a reprimir la oposición, al igual que medidas dirigidas a fortalecer las estructuras estatales. Unas y otras contribuyeron a crear un Estado más capaz de ejercer su dominio sobre el territorio y la población nacionales. Por un lado, la construcción de un sistema de carreteras agilizó la movilización de las tropas; por el otro, el control de los recursos financieros del Estado les brindó la posibilidad de fortalecer aquellos programas y organismos estatales más funcionales a los nuevos esquemas de dominación diseñados por los estadunidenses. En conjunto, el resultado de tales medidas fue una mayor injerencia del Estado sobre las masas rurales, que constituían la inmensa mayoría de la población de la República Dominicana. En algunos casos, los ocupantes continuaron aplicando políticas estrenadas previamente por los gobernantes dominicanos, en general con éxitos mediocres; en otros casos, implantaron otras diseñadas por ellos mismos, encaminadas a la modernización del Estado. ${ }^{22}$ La política de tierras del régimen de ocupación y el sistema de trabajo obligado en las carreteras constituyen ejemplos de lo primero; sus políticas contributivas, aunque amparadas en las leyes agra-

${ }^{22}$ Calder, Impacto, 1989. rias, fueron, por el contrario, de factura estadunidense.

Uno de los derivados de las leyes agrarias fue la creación del Tribunal de Tierras, en 1920, mediante una orden ejecutiva del gobernador militar que revisaba la "Ley de registro de la propiedad territorial" de 1912. El Tribunal contaba con organismos de apoyo a su labor principal, que estribaba en sanear los títulos de la propiedad agraria. Como era de esperarse, este Tribunal jugó un papel de importancia en la creación de los marcos institucionales y legales para el surgimiento y la expansión de grandes corporaciones azucareras de capital estadunidense. Aunque las medidas expropiatorias de las corporaciones generaron una oleada de protestas en el este del país que desembocó en la rebelión, el Tribunal de Tierras fue una pieza clave para validar la situación legal que reclamaban los nuevos amos de la tierra. ${ }^{23}$ Aun así, las actuaciones del Tribunal fueron desiguales; aparentemente, sus efectos se sintieron primero en las provincias del este, en tránsito hacia el monocultivo azucarero. En otras regiones, el Tribunal de Tierras comenzó a actuar mucho más tarde; en la provincia de Santiago, parece que el grueso de sus gestiones se concentró en las décadas de los treinta y los cuarenta. Futuros estudios sobre su funcionamiento deben precisar cuáles fueron sus efectos sobre la estructura agraria de regiones en específico; es de esperarse que, en algunas zonas, el

${ }^{23}$ Calder, Impacto, 1989, pp. 133-195; Marínez, Resistencia, 1984, pp. 47-69. 
Tribunal no haya cumplido el papel expropiatorio que jugó en el este.

Con todo, la intervención estadunidense dejó una huella profunda sobre la estructura agraria dominicana y, en consecuencia, sobre amplios sectores campesinos; entre otras razones, porque los estadunidenses usaron la reorganización del sistema de propiedad para transformar las bases fiscales del Estado. En tal sentido, al viejo propósito de modernizar el sistema de tierras, aunaron el de modernizar el sostén económico de las estructuras de poder. A tales efectos, aprobaron en 1919 la Ley del impuesto territorial. Como ha destacado Calder, su propósito era generar fuentes de ingreso que sustituyesen las existentes hasta el momento, fundadas en los impuestos sobre el comercio exterior y en las contribuciones indirectas. A cambio, intentaron ampliar las fuentes de contribución directa, creando un impuesto sobre la propiedad. ${ }^{24}$ En síntesis, la ley implicaba una disminución de los ingresos estatales provenientes del comercio exterior y un aumento de los provenientes de las rentas internas, en forma particular, de los que se originaban en las actividades agropecuarias. Su aplicación conllevaba un incremento sustancial en el peso contributivo que recaía sobre la población dominicana; por mera lógica demográfica, el campesinado habría de cargar con buena parte del mismo.

No fue sorpresa, por tanto, que el campesinado repudiase esos intentos. Un estudio regional muestra que

${ }^{24}$ Calder, Impacto, 1989, pp. 163-167. los campesinos del Cibao se negaron a pagar tal impuesto. La evidencia existente sugiere que su resistencia alcanzó niveles considerables. ${ }^{25}$ Entre otras cosas, el impuesto territorial representó un nuevo tipo de contribución, ajena a las prácticas del país y a sus condiciones económicas y sociales. Proporcionalmente, representaba una carga fija sobre el presupuesto de las familias campesinas, y debía ser pagado tanto en los buenos como en los malos tiempos. De acuerdo con algunos estudiosos, este tipo de impuesto resulta particularmente pernicioso sobre los sectores campesinos, cuyos ingresos están sujetos a una diversidad de factores, y cuya supervivencia depende de un precario equilibrio que deben mantener a toda costa. ${ }^{26}$ Para algunos grupos de campesinos al menos, el impuesto territorial amenazaba con alterar ese frágil equilibrio. Por ello se negaron a pagar, a inscribir sus propiedades en los registros oficiales y a ofrecer información a las autoridades sobre el tamano de sus fincas y sobre su producción. Y aunque este tipo de oposición no desembocó en una resistencia armada, como ocurrió entre el campesinado despojado del este, sus acciones fueron lo suficientemente enćrgicas como para producir la alteración de los planes estatales.

Resistencia similar enfrentaron las autoridades estadunidenses al tratar de implantar la Ley de caminos, aprobada originalmente en 1907, aunque

\footnotetext{
${ }^{25}$ San Miguel, "Estado", 1991, pp. 54-58, y "Peasant", 1995, pp. 48-54.

${ }^{26}$ Scott, Moral, 1976.
} 
hasta el periodo de la ocupación había tenido escasos resultados ${ }^{27}$ Esta ley estableció un sistema de "prestaciones laborales" -en realidad, un sistema de trabajo obligatorio- con el fin de mejorar las condiciones de las carreteras y los caminos. En sustitución de los cuatro días de trabajo que se requerían, los prestatarios podían pagar un "impuesto de exoneración", ascendente originalmente a dos pesos. Aun así, para numerosos campesinos tal impuesto resultaba oneroso, por lo que su pago fue resistido; también resistieron el trabajo obligatorio. Aunque parcial, la evidencia disponible sugiere que la oposición a la Ley de caminos alcanzó gran amplitud entre el campesinado. Tanto las autoridades municipales como las estatales tuvieron que asumir posturas enérgicas ante el masivo rechazo al trabajo obligado. Los evasores eran arrestados y llevados a trabajar como prisioneros; algunos recibieron multas por evadir el trabajo en los caminos y las carreteras. Ante la oposición de las masas rurales, sobre todo a raíz de la crisis económica que afectó a la región norte de la República Dominicana a principios de los años veinte, las autoridades militares redujeron $\mathrm{el}$ "impuesto de caminos" a un peso, además de eliminar el trabajo "prestatario". Tales cambios produjeron cierto alivio al campesinado, aunque el impuesto de caminos continuó siendo muy impopular. Una década

\footnotetext{
${ }^{27}$ Lo siguiente se basa en San Miguel, "Estado", 1991, pp. 50-54, y "Peasant", 1995, pp. 4448.
}

más tarde, bajo la dictadura de Rafael L. Trujillo, el trabajo prestatario renació con nuevos bríos.

El periodo de la ocupación estadunidense fue crucial en términos de las relaciones entre el Estado y el campesinado. Como hemos visto, en esos años el Estado fue capaz de ejercer mayor presión sobre las masas rurales. Tanto a través de las leyes agrarias como de la Ley de caminos, los organismos estatales se dejaron sentir de manera contundente sobre la vida del campesinado; su trabajo, sus ingresos monetarios y sus tierras se vieron más sujetos a la regulación, la exacción y la fiscalización por parte del listado. En tal sentido, podemos considerar que los estadunidenses inauguraron una nueva fase en el proceso de "domesticación" del campesinado por parte del Estado. Incapaces de modernizar las prácticas económicas de los sectores rurales, el gobierno de ocupación optó por una política autoritaria, orientada a imponer nuevos esquemas de dominación sobre la ruralía. Y este legado prevaleció luego de la salida de las tropas estaduniden. ses en 1924 .

En 1930, Trujillo ascendió al poder, estableciendo un régimen dictatorial que se prolongó hasta su asesinato, en 1961. Varios de los planes económicos de su régimen se basaron en la explotación del campesinado. En efecto, los campesinos fueron usados como mano de obra en fincas privadas -sobre todo en las del tirano y sus allegados-, como productores de bienes para el consumo nacional y para la exportación, al igual que como productores de materia prima 
para las agroindustrias del país ${ }^{28}$ Para lograr sus propósitos, el dictador recurrió tanto a la coacción como a medidas "fomentalistas", destinadas a aumentar la producción agraria de base campesina. Entre las primeras medidas se destacó el "programa de riego" y su política de caminos, que, siguiendo las pautas sentadas por los estadunidenses entre 1916-1924, recurrió al trabajo prestatario con el fin de construir canales de riego y vías de transporte. En algunas zonas del país, la movilización de campesinos alcanzó cifras considerables; tal fue el caso de aquellas regiones que contaban con un gran potencial agrícola, pero constreñido por la falta de agua. Y a pesar de que hubo oposición y resistencia al trabajo prestatario, al igual que bajo la ocupación estadunidense, las autoridades contaron en esta ocasión con medios mucho más eficaces para lograr sus propósitos. El fortalecimiento del Estado bajo la ocupación de Estados Unidos posibilitó el uso del ejército en el reclutamiento de los prestatarios y en la persecución de los refractarios al trabajo compulsorio. Igualmente, los organismos de poder regional fueron integrados plenamente a los esquemas de poder estatal, convirtiéndose los ayuntamientos y las gobernaciones provinciales en eficientes colaboradores en los proyectos de la dictadura. No está de más indicar que, para muchos miembros

\footnotetext{
${ }^{2 \theta}$ San Miguel, "Estado", 1991, pp. 58-74. La obra sobre la dictadura trujillista es amplia $y$ diversa. Entre los trabajos más pertinentes a los temas que abordo en esta sección se encuentran Cassá, Capitalismo, 1982; Marínez, Agroindustria, 1993; Inoa, Estado, 1994.
}

de las elites regionales, tales proyectos representaban signos del progreso material que se comenzaba a vivir bajo el régimen trujillista. Trujillo finalmente hacía posibles sus sueños de "modernización"; para las elites, su mano dura era "necesaria" para la regeneración de la nación. ${ }^{29}$

La euforia con la construcción de canales de riego y de carreteras duró hasta mediados de los años cuarenta; entonces tendió a disminuir el uso de los campesinos como prestatarios en esas obras, aunque el mismo no desapareció cel todo durante la tiranía. Tampoco desapareció -por el contrario, puede que haya aumentado con el tiempo- el uso de presidiarios en las obras públicas y en empresas privadas, sobre todo, en las fincas arroceras del dictador y de miembros de su claque; esas fincas se caracterizaban por su insalubridad y su alto nivel de mortalidad ${ }^{30}$

Más permanente a lo largo de la tiranía fue el fomento de la agricultura, que no dejó de tener efectos favorables sobre determinadas regiones donde prevalecía la producción campesina. La extensión del riego fue una de las medidas para incrementar la producción agrícola, sobre todo la de arroz. Con el riego se logró expandir la frontera agrícola; en algunas zonas se repartieron tierras irrigadas a campesinos. En otras áreas se establecieron colonias agrícolas en las que el

${ }^{29}$ Véase Mateo, Mito, 1993.

${ }^{30}$ Todavía carecemos de un estudio sobre tan importante fuente de trabajo durante el trujillato. Hay algunas referencias al trabajo de los presidiarios en varias memorias sobre la época de la dictadura. 
gobierno, además de distribuir tierras, ofrecía herramientas, semillas y crédito a los agricultores; también se solía ofrecer asesoramiento técnico con el fin de mejorar la calidad de las cosechas, sobre todo, de los productos destinados a la exportación. El resultado del conjunto de estas medidas fue vincular a amplios sectores campesinos a la economía de mercado, uno de los fines principales de la política agrícola del régimen. No obstante, al finalizar la segunda guerra mundial y abrirse nuevamente los mercados europeos, hubo una tendencia a restar apoyo estatal a la producción campesina. Hacia la segunda mitad de los años cuarenta, se prestó más atención al fomento de la agricultura de gran escala, incluyendo a la caña de azúcar, cultivo en el cual el mismo Trujillo realizó inversiones considerables. Aun así, ciertos renglones agrícolas -como el tabaco, el café y el cacao, al igual que la producción de víveres destinada al mercado interno- continuaron siendo dominados por los pequeños y medianos productores.

No obstante, hay que subrayar que, bajo la dictadura trujillista, cambió de manera radical la relación entre el campesinado y el Estado. Al iniciarse la "Era de Trujillo", el campesinado no había sido sometido totalmente al poder estatal. Aunque bajo la ocupación estadunidense avanzó notablemente su sujeción al Estado, a principios de los años treinta la misma no era un proceso acabado. Pero en esa década, el Estado aumentó de forma sistemática su hegemonía sobre las masas rurales. En algunos casos, ello se logró a través del terror y la represión; en otros, se recurrió al reparto de tierras, a la extensión del crédito y al fomento de las actividades económicas propias de los sectores campesinos. Generalmente se combinaron la coacción y las concesiones económicas con el fin de lograr la aquiescencia de los campesinos. El resultado final fue la consolidación del poder trujillista. Así, a pesar de que, en diversas partes del país, los campesinos fueron despojados de sus tierras por el tirano o por alguno de sus allegados, lo cierto es que Trujillo $-\mathrm{y}$, por ende, el poder estatal- llegó a contar con una amplia base de apoyo entre el campesinado. La sujeción del campesinado fue un resultado de la conversión del Estado en un agente capaz de mediar entre los diversos sectores de la sociedad dominicana. $\mathrm{Al}$ aumentar su papel de mediador, el Estado logró, también, que amplios sectores del campesinado dependiesen de él para obtener tierras, implementos de trabajo, crédito, asesoramiento técnico, agua de riego y otros recursos necesarios para la producción. Junto a un eficiente aparato de vigilancia y represión, capaz de alcanzar los lugares más remotos del país, este papel del Estado como dador de bienes hizo que los campesinos aceptaran su sujeción al mismo.

\section{El CAMPESINADO EN LA "TRANSICIÓN DEMOCŔ́TICA"}

Con el asesinato de Trujillo, en 1961, se inició una época de transformaciones significativas en la República 
Dominicana. En un breve lapso de tiempo, el monolítico régimen trujillista se desmoronó, posibilitándose la elección de un presidente de vocación democrática y populista. Sin embargo, el gobierno de Juan Bosch duró apenas unos meses; un golpe de Estado (septiembre 1963), seguido por una guerra civil y una intervención estadunidense (1965) contribuyeron a cambiar el espectro político del país. En 1966 se celebraron nuevas elecciones, en las que salió victorioso Joaquín Balaguer, un cercano colaborador de Trujillo y candidato favorecido por las autoridades estadunidenses frente a Bosch. Entonces se inició lo que se conoce como el "gobierno de los doce años", caracterizado por su autoritarismo y por el uso del terror contra la oposición. Balaguer se mantuvo en el poder hasta 1978, cuando fue derrotado por el candidato del Partido Revolucionario Dominicano, Antonio Guzmán. Bajo Guzmán se inició un periodo de relativa apertura política que propició el surgimiento de organizaciones políticas y sociales cuya existencia había sido imposibilitada por la represión balaguerista. Entre ellas hubo muchas organizaciones campesinas, cuyos fines y motivos variaban de una a otra. ${ }^{31}$

En los años de la "transición democrática", la relación entre el Estado y el campesinado adquirió nuevos

${ }^{31}$ Los estudios sobre el periodo posterior a 1961 son abundantes. Se pueden consultar: Betances, Siate, 1995, pp. 113-133; Gleijeses, Crisis, 1985; Lowenthal, Dominican, 1972; Cassá, Doce, 1986; Lozano, Reformismo, 1985; Marínez, Democracia, 1994. significados. Los campesinos, auncue marginados del poder, se convirtieron en un sector social al que había que ganarse políticamente. No obstante que la represión y las medidas autoritarias se dejaron sentir sobre el campesinado, lo cierto es que la existencia de un sistema de partidos y de elecciones implicó que los diversos movimientos políticos trataran de ganárselo. Ello fue así tanto en los sectores oficialistas, que usaron los recursos estatales para obtener el apoyo de los campesinos, como en las organizaciones de oposición, que también intentaron ampliar su base entre ellos.

Varias de las políticas económicas del Estado contribuyeron a ganar para éste el apoyo de amplios sectores campesinos. Por ejemplo, entre los campesinos con acceso a la tierra -propietarios, arrendatarios o aparceros- las agencias gubernamentales distribuyeron recursos para fomentar la producción agrícola. Así, el crédito, la distribución de semillas y agroquímicos, y el asesoramiento técnico suministrado por agencias, como la Secretaría de Agricultura, el Banco Agrícola, y el Instituto del Tabaco, jugaron un papel fundamental en el logro de la aquiescencia del cam. pesinado. ${ }^{32} \mathrm{~A}$ través de la distribución de esos recursos económicos entre los agricultores, combinada con una presencia vigilante de los organismos represivos del Estado, el presidente Ba-

\footnotetext{
${ }^{32}$ Solore las condiciones de la ruralía en las décadas recientes, resulta útil la colección de ensayos que aparecen en: Asociación, Problemática, 1983.
} 
laguer fue capaz de convertir al campesinado en uno de los sostenes de su régimen. Al respecto, hay que destacar también su uso de medios "teatrales" para proyectar su vínculo con el campesinado. Entre éstos hay que mencionar su realización de "obras sociales" en la ruralía (fundación de escuelas, construcción de caminos, etc.), cuya inauguración era usada como "escenario" para proyectar una supuesta empatía con el campesinado. En tales ocasiones, los campesinos recibían dádivas directamente del gobernante; por ejemplo, entre las mujeres se repartían máquinas de coser; entre los hombres, herramientas de trabajo. Igualmente, se permitía a algunos campesinos presentar sus quejas a Balaguer o hacerle peticiones especiales. De tal forma, ante los desmanes, la ineficiencia o la indiferencia de los funcionarios de menor rango, el gobernante proyectaba una imagen de protector del campesinado.

Medidas como la distribución de insumos y la concesión de crédito tuvieron pocos efectos positivos sobre los campesinos sin tierra. Entre ellos, fue la expectativa de obtener tierra por mediación estatal lo que incidió de forma más decisiva sobre sus actitudes ante el Estado y el régimen balaguerista. De hecho, se puede afirmar que, independientemente de sus implicaciones económicas y sociales, la distribución de tierras, en las décadas de los sesenta y los setenta, fue un instrumento político, dirigido a disminuir las tensiones sociales en la ruralía y, en consecuencia, a fortalecer al Estado. Fundado en 1962, el Instituto Agrario Dominicano fue el organismo encargado de organizar la reforma agraria. En buena medida, el IAD fue una criatura de los acuerdos de Punta del Este que, como se sabe, fueron una respuesta a los retos políticos y sociales a nivel hemisférico planteados por la revolución cubana. ${ }^{33}$

Sin embargo, a pesar de las proclamas oficiales sobre la deseabilidad de la reforma agraria, la misma marchó a ritmo sumamente lento durante los años sesenta. De hecho, algunas de las zonas donde se distribuyó tierra fueron áreas donde los campesinos habían sufrido despojos masivos durante la dictadura trujillista. En varias de ellas, los campesinos, recién caída la dictadura, se lanzaron a recuperar las tierras de que habían sido despojados ellos o sus antecesores. En tales casos, el IAD se circunscribió a legalizar una "reforma agraria" hecha por los campesinos mismos. En general, la actuación del IAD durante la década de los sesenta fue mediocre; la política de recuperación de tierras y de creación de asentamientos campesinos no siguió criterios económicos y sociales claros. Además, debido al centralismo que ha caracterizado a la estructura de poder en la República Dominicana, la reforma agraria dependió en buena medida de la voluntad presidencial. Así, bajo el gobierno de Balaguer entre 1966 y 1978, la reforma agraria se estableció a partir de un criterio eminentemente político. ${ }^{34}$

\footnotetext{
${ }^{33}$ Fernández Reyes, Ideologías, 1986, especialmente pp. 23-52.

${ }^{34}$ Dore, Reforma, 1981, y Problemas, 1982.
} 
La situación comenzó a cambiar hacia fines de los años sesenta, cuando campesinos de diversas partes empezaron a organizar ocupaciones de tierras. En los inicios de la década de los setenta, las ocupaciones de tierra se habían convertido en una situación cotidiana. $Y$ aunque las mismas tuvieron mayor incidencia en unas regiones del país que en otras, lo cierto es que hubo ocupaciones en virtualmente todas las regiones del país. Las ocupaciones de tierra de principios de los setenta constituyeron uno de los momentos álgidos de las luchas campesinas, mismas que pusieron a prueba la retórica oficial en torno a la cuestión agraria. Las movilizaciones campesinas jugaron un papel crucial al debilitar las alianzas de clase que sustentaban al bloque de poder. Por su parte, el presidente Balaguer, siempre atento a lo que más convenía a sus intereses políticos, no dejó de aprovechar las movilizaciones en el campo para mantener su adhesión entre el campesinado. No debe extrañar, entonces, que sectores de las clases latifundistas expresasen su oposición a la retórica agrarista de Balaguer. La oposición de estos grupos al agrarismo oficial alcanzó su máxima expresión a partir de 1972 , cuando se aprobó el denominado "código agrario", conjunto de leyes que vitalizaron la reforma agraria. ${ }^{35}$

Durante los años setenta, la reforma agraria marchó más rápidamente.

${ }^{35}$ Maríñez, Resistencia, 1984, pp. 108-129; Eusebio Pol, "Ocupaciones", 1982, pp. 160 179; y Dore y Eusebio, "Movimiento", 1987, pp. 253-276.
La Comisión de Recuperación de Tierras del Estado (CRTE), creada como parte del código agrario, se convirtió en un verdadero foro de denuncias de los despojos sufridos por los campesinos y de las ocupaciones ilegales de tierra realizadas por empresarios, funcionarios del gobierno y militares. En tal contexto, miles de campesinos se organizaron con el fin de ocupar tierras, realizar denuncias ante la CRTE o resistir los intentos de desalojo por parte de los latifundistas. Y aunque Balaguer trató de manipular a las organizaciones campesinas para sus propios fines, lo cierto es que muchas de ellas comenzaron a mostrar una total independencia de acción frente a los funcionarios del gobierno y a los activistas que operaban en el campo a nombre del oficialismo. Algunos dirigentes campesinos se identificaron con los grupos de izquierda que intentaron ganar adeptos entre el campesinado y que, en consecuencia, orientaron su proselitismo hacia el campo. La acción de estos grupos contribuyó al surgimiento de organizaciones campesinas que se fueron distanciando del agrarismo oficial y que reclamaban una reforma agraria más radical y abarcadora.

Resultados similares tuvieron los vínculos de la Iglesia católica con las organizaciones campesinas. De hecho, la Iglesia católica fue una de las primeras instituciones en realizar una labor organizativa entre el campesinado, a principios de los años sesenta. Entonces hubo religiosos y religiosas que establecieron vínculos directos con comunidades campesinas. Como ha sido común en otras partes de Amé- 


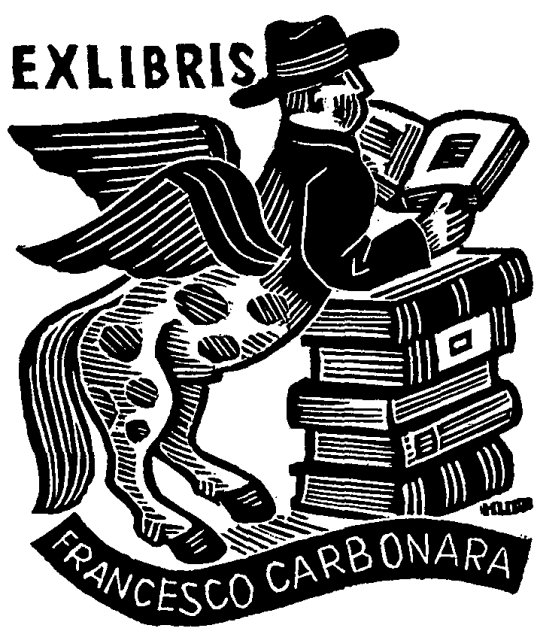

rica Latina y el Caribe, esos vínculos terminaron por transformar tanto a los campesinos como a los religiosos y religiosas que trabajaron en las comunidades rurales. Por un lado, en los años sesenta y setenta, cuando el autoritarismo oficial limitaba las posibilidades de que los campesinos crearan organizaciones propias, autónomas de las instituciones estatales, las relaciones de los campesinos con los sacerdotes y las monjas les brindaron un pequeño resquicio que les permitió desarrollar luchas por obtener tierra, crédito y servicios estatales. Estas experiencias contribuyeron, también, a generar un liderato campesino, el que no siempre siguió las directrices de sus mentores de la Iglesia católica. Hubo algunos que rompieron con las organizaciones religiosas por considerar que no estaban dispuestas a asumir posturas más radicales frente a los urgentes dilemas que confrontaba el campesinado dominicano en ge. neral. Algunos de ellos encontraron nuevos aliados en las agrupaciones de izquierda; otros optaron por fundar organizaciones nuevas, sin lazos formales ni con los últimos ni con la Iglesia. En todo caso, para mediados de la década de los setenta era evidente que Balaguer perdía terreno entre las masas rurales. Muchas de las expectativas generadas a raíz de la aprobación del código agrario mostraron ser falsas. Por su parte, amplios sectores de campesinos encontraron nuevos aliados en grupos políticos y religiosos que, por una causa u otra, trataban de ganar adeptos entre el campesinado. La erosión de la imagen de Balaguer se evidenció en 1978 cuando no sólo perdió las elecciones, sino que su candidatura sufrió serios reveses en áreas rurales en las que tradicionalmente había obtenido un apoyo sustancial.

La ascensión al poder del PRD marcó algunos cambios importantes en las relaciones entre el Estado y el campesinado, sobre todo en la esfera política. Bajo la presidencia de Antonio Guzmán (1978-1982) disminuyó notablemente la represión contra la oposición, lo que propendió a la creación y al fortalecmiento de las organizaciones campesinas. A todo lo largo y ancho del país florecieron las organizaciones de campesinos; en algunos casos, se trataba de instrumentos de lucha por la tierra; en otros, para luchar por los servicios estatales; en 
otros más, organismos para garantizar la canalización de crédito e insumos productivos a los agricultores. A pesar de su diversidad de miras y propósitos, la coyuntura de fines de los setenta e inicios de los ochenta constituyó un momento de ebullición de las luchas campesinas, cuando se presenció la fundación de organizaciones con pretensiones de incluir a los campesinos de todo el país. Entre estas últimas hay que mencionar al Movimiento Campesino Independiente (MCI) y a la Confederación Nacional Campesina (CNC). En esos años, se evidenció el surgimiento de organizaciones encaminadas a confrontar situaciones inéditas en la República Dominicana que afectaban negativamente al campesinado. Irónicamente, en esa época también se comenzó a manifestar el creciente abandono en que el Estado dejaba al campesinado.

\section{LA "POLÍtTICA DEL ABANDONO"}

Durante las décadas de los sesenta y los setenta la economía dominicana continuó dependiendo de las exportaciones agrícolas. Al azúcar, principal producto de exportación en esos años, le seguían el café, el cacao y el tabaco, los que eran producidos en gran medida en propiedades de pequeño y mediano tamaño. Por ello, el Estado continuaba destinando recursos económicos y ayuda técnica hacia esas actividades productivas. No obstante, desde los años sesenta se comenzó a traslucir el creciente apoyo del Estado a otros sectores económi-

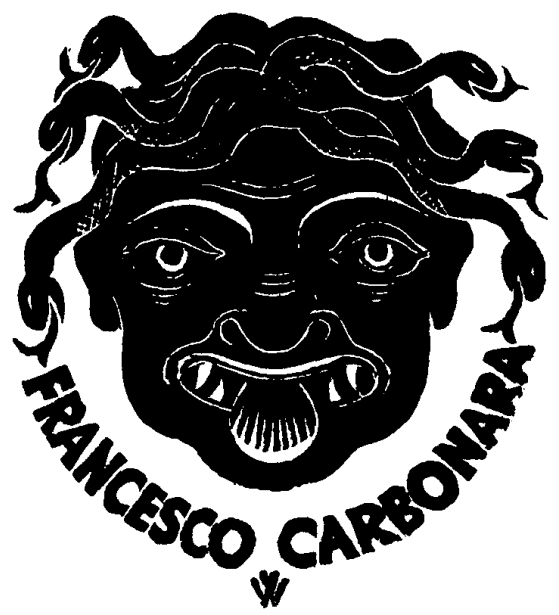

cos, de manera particular a aquellos que podían contribuir a las políticas modernizadoras en boga: La minería, la industria y el turismo recibieron una tajada cada vez mayor de los recursos estatales. De igual forma, se prestó mayor énfasis al desarrollo de las agroindustrias modernas, usualmente de capital foráneo, en detrimento de los productos tradicionales de exportación en los que el campesinado continuaba jugando un papel significativo. Así, en las últimas dé. cadas, la política económica del Estado, tanto bajo las administraciones del Partido Reformista como las del Partido Revolucionario Dominicano, se han orientado hacia el fomento dc los sectores económicos "modernos", dejando de lado a los productores ru- 
rales tradicionales, sobre todo a los campesinos. Esta es la política que podemos denominar del "abandono". ${ }^{36}$

La misma ha tenido diversas expresiones. Una de ellas ha sido el uso de enormes cantidades de terreno en el establecimiento de tal tipo de empresa. Empresas mineras como la Falconbridge, la Alcoa y la Rosario Mining (luego Rosario Dominicana) ejemplifican este patrón. Estas empresas mineras han contribuido directamente al desplazamiento de una gran cantidad de familias campesinas; la contaminación ambiental provocada por ellas, por otro lado, ha contribuido al deterioro de las condiciones de vida de los habitantes de las regiones aledañas a las minas. ${ }^{37}$ Los efectos nocivos de la minería sobre el campesinado han conllevado el surgimiento de movimientos de protesta en contra de las políticas estatales, la destrucción de las comunidades y la contaminación producida por esas empresas. En los años setenta y ochenta, tales protestas llegaron a producir movilizaciones masivas que señalaban una tendencia novedosa en la República Dominicana: las comunidades rurales afectadas por las empresas mineras se convirtieron en la punta de lanza de un

\footnotetext{
${ }^{36}$ Véase Fernández Reyes, Ideologias, 1986; Lozano, Reformismo, 1985; Castillo, et al., Gulf, 1974; Cordero, et al., Tendencias, 1975; Ferrán, Tabaco, 1976; Dore, Alternativas, 1987; Moya, Empresarios, 1992.

${ }^{37}$ Albuquerque, "Historia", 1984, pp. 57-75. La revista iAboral de los años setenta contiene una buena cantidad de artículos sobre las minas, sus efectos ecológicos, y sus consecuencias sobre las conunidades campesinas.
}

amplio movimiento de defensa del ambiente que ha logrado aglutinar a amplios sectores sociales. ${ }^{38}$

La construcción de represas destinadas a la producción de energía eléctrica y a garantizar el suministro de agua a las áreas urbanas e industriales, es un ejemplo igualmente importante sobre las tendencias señaladas anteriormente. Por su magnitud, las represas han implicado la destrucción de numerosas comunidades, incluso algunas de ellas dedicadas a actividades económicas relativamente estables, como el cultivo del café. Sin embargo, imbuidas por el desarrollismo, las autoridades han fomentado la construcción de presas en diferentes puntos del país; en ocasiones, para los campesinos de esas regiones las consecuencias han sido tan nocivas como las de la minería. En tales áreas, los campesinos han dirigido movilizaciones y luchas sociales apoyados por otros sectores. A veces han contado con el apoyo de miembros de la Iglesia católica y de grupos ecologistas. ${ }^{39}$

El apoyo a la construcción de represas y a actividades económicas como la minería no son, sin embargo, la única manera en que el Estado ha evidenciado su creciente abandono del campesinado. Su política contributiva, el incentivo a las agroindustrias, la disminución de los créditos y los recursos destinados a la agricultura campesina, y su dejadez ante la reforma agraria son elementos adicionales que muestran esa tendencia. En los últimos años, al confrontar dificultades la

\footnotetext{
${ }^{38}$ San Miguel, "Luchas", 1997.

${ }^{39} \mathrm{Ibid}$.
} 
minería y la agroindustria del azúcar, el Estado ha incentivado sectores como el turismo, el cual también contribuye a reducir la tierra y los recursos económicos disponibles para las actividades económicas campesinas. Hoy en día los campesinos ven cómo, las agencias estatales orientadas hacia la agricultura, cuentan cada vez con menos recursos, mientras que se destinan medios considerables a otros fines, algunos tan superfluos como el monstruoso y fascistoide Faro de Colón.

\section{CONCLUSIONES}

En este trabajo he tratado de mostrar las etapas históricas de las relaciones entre el Estado y el campesinado en la República Dominicana. Ante todo, quiero sugerir que esas relaciones han contado, en el pasado siglo y medio, con tres grandes fases o etapas. La primera se puede ubicar entre 1844, año de fundación de la república, y 1916, cuando se inició la ocupación estadunidense que habría de durar hasta 1924. En esta fase, el Estado fue incapaz de imponer su hegemonía sobre el campesinado, a pesar de que su "domesticación" se veía como parte del proyecto civilizador auspiciado por los sectores letrados y los grupos dominantes del país. Para ellos, la domesticación del campesinado era fundamental tanto por razones económicas como políticas. En relación con lo primero, se vislumbraba el desarrollo de una economía moderna basada en una gran masa campesina que, bajo los auspi- cios estatales y de los organismos corporativos del empresariado nacional (como las Cámaras de Comercio), pudiese responder adecuadamente a los imperativos del mercado y a las exigencias fiscales del Estado.

La segunda etapa se inició precisamente con la ocupación estadunidense de 1916-1924. En esos años, se pusieron en vigor medidas que permitieron al poder estatal ampliar su control sobre las masas rurales. $\mathrm{Si}$ bien es cierto que los campesinos respondieron a tales intentos de dominio de diversas maneras, también lo es que el régimen interventor contribuyó de forma decisiva a fortalecer al Estado y que, en consecuencia, sentó las bases para que, bajo la dictadura de Trujillo, se extendiese como nunca antes la hegemonía estatal sobre los sectores campesinos. Bajo su régimen (1930-1961), el poder del Estado alcanzó niveles inéditos; en este periodo, alcanzó mayor intensidad y amplitud la "domesticación" de las masas rurales. Esa "domesticación" se logró a través de la combinación de medidas de fomento a la economía campesina con medidas represivas.

Esa combinación continuó durante los años sesenta y setenta bajo la presidencia de Joaquín Balaguer. Sin embargo, las transformaciones económicas, sociales, políticas y culturales que ocurrieron en esos años comenzaron a resquebrajar la subordinación del campesinado al balaguerismo. La misma existencia de un sistema electoral, aunque sumamente defectuoso, implicó que las masas rurales debían ser "cortejadas" con los recursos estatales. Por otro lado, la mayor porosidad 
de las comunidades rurales a las influencias políticas, sociales y culturales de agentes "externos", cada vez más diversos y amplios, brindó nuevas oportunidades organizativas a los campesinos. Ansiosos por crear mecanismos para mejorar sus condiciones de vida, y dispuestos a entablar alianzas que les permitieran fortalecer su capacidad de negociación y regateo frente al Estado y los sectores de poder, los campesinos encontraron, a partir de los años sesenta, diversos grupos dispuestos a establecer tales relaciones. Ello facilitó movilizaciones y luchas sociales totalmente novedosas entre el campesinado, el cual alcanzó, en las décadas de los setenta y los ochenta, un protagonismo social que no había tenido desde la época de las "revoluciones" y las "gavillas" de fines del siglo XIX y principios del $\mathrm{XX}$, cuando las elites abogaban por un Estado fuerte que posibilitáse su "domesticación".

Pero cuando el campesinado alcanzó una mayor capacidad de movilización, se comenzó a evidenciar su erosionamiento económico como resultado de las políticas estatales y de las tendencias económicas globales. Durante la década de los ochenta, la República Dominicana, al igual que el resto de los países de América Latina y el Caribe, fue víctima de los reordenamientos económicos mundiales -es decir, de la tan mentada "globalización"-, los que incidieron negativamente sobre las clases populares, incluyendo al campesinado. El mismo deterioro de las condiciones de vida en la ruralía ha impulsado una masiva emigración hacia las ciudades que ha conllevado una reestructuración del espectro social y político del país. Hoy en día, la población rural juega un papel cada vez menos importante en la estructura política y económica de la República Dominicana. Irónicamente, después de intentar por más de un siglo "domesticar" a las masas rurales, el poder les da la espalda a quienes constituyeron el objeto de su gran proyecto "civilizador", concebido a partir del doble pilar del mercado y del Estado nacional.

\section{BIBLIOGRAFÍA}

-Albuquerque, Alcibiades, Títulos de los terrenos comuneros en la República Dominicana, Impresora Dominicana, Ciudad Trujillo, 1961.

-Albuquerque, Ramón, "Historia de la minería dominicana", en Tabaco, azúcar $y$ minería, Banco de Desarrollo Interamérica, S.A. /Museo Nacional de Historia y Geografía, Santo Domingo, 1984, pp. 57-75.

-Asociación Dominicana de Sociólogos, Problemática rural en República Dominicana: III Congreso de Sociología, Alfa \& Omega, Santo Domingo, 1983.

-Baud, Michel, Peasants and tobacco in the Dominican Republic, 1870-1930, University of Tennessee Press, Knoxville, 1995.

- "Transformación capitalista y regionalización en la República Dominicana, 1875-1920", Investigación y Ciencia, vol. I, núm. 1, 1986, pp. 17-45.

-Betances, Emelio, State and society in the Dominican Republic, Westview Press, Boulder, 1995.

-Boin, Jacqueline y José Serulle Ramia, El proceso de desarrollo del capitalismo en la República Dominicana (1844. 1930), vol. I. El proceso de transforma- 
ción de la economía dominicana (1844 a 1875), Gramil, Santo Domingo, 2a ed., 1981; y vol. II: El desarrollo del capitalismo en la agricultura (1875-1930), Gramil, Santo Domingo, 1981.

-Bonó, Pedro F., El montero [1848], Julio D. Postigo e Hijos, Santo Domingo, 1968.

-Bosch, Juan, Camino real [1933], Alfa \& Omega, Santo Domingo, 3 a ed. facsimilar, 1983.

La mañosa [1936], Alfa \& Omega, Santo Domingo, 21 ed., 1994.

-Brea, Ramonina, Ensayo sobre la formación del Estado capitalista en la República Dominicana y Haití, Taller, Santo Domingo, 1983.

-Bryan, Patrick, "La producción campesina en la República Dominicana a principios del siglo xx", Eme-Eme: Estudios Dominicanos, vol. VII, núm. 42, 1979, pp. 29-62.

-Calder, Bruce, El impacto de la intervención: La República Dominicana durante la ocupación norteamericana de 1916-1924, Fundación Cultural Dominicana, Santo Domingo, 1989.

-Cassá, Roberto, Capitalismo y dictadura, Universidad Autónoma de Santo Domingo, Santo Domingo, 1982.

- Los doce años: Contrarrevolución y desarrollismo, Alfa \& Omega, Santo Domingo, 1986.

-Clausner, Martin, Rural Santo Domingo: settled, unsettled and resettled, Temple University Press, Filadelfia, 1973.

-Corclero, Walter, et al., Tendencias de la economía cafetalera dominicana, 1955-1972, Universidad Autónoma de Santo Domingo, Santo Domingo, 1975.

-Castillo, José del, "La formación de la inclustria azucarera moderna en la República Dominicana" en Tabaco, azúcar y minería, Banco de Desarrollo Interamérica, S.A. Museo Nacional de Historia y Geografía , Santo Domingo, 1984, pp. 23-56.

, et al., La Gulf \& Western en República Dominicana, Universidad
Autónoma de Santo Domingo, Santo Domingo, 1974.

-Derby, Lauren, "Haitians, magic, and money: Raza and society in the haitiandominican borderlands, 1900 to 1937", Comparative Studies in Society and History, vol. 36, núm. 3, 1994, pp. 488-526.

-Domínguez, Jaime de Jesús, La sociedad dominicana a principios del siglo $\mathrm{xx}$, Colección del Sesquicentenario de la Independencia Nacional, Santo Domingo, 1994.

-Dore Cabral, Carlos, Problemas de la estructura agraria dominicana, Taller, Santo Domingo, 2a ed., 1982.

- Reforma agraria y luchas sociales en la República Dominicana, 1966-1978, Taller, Santo Domingo, 1981.

- (coord.), Alternativas de política agraria, INTEC, Santo Domingo, 1987.

- y Noris Eusebio, "El movimiento campesino dominicano" en PierreCharles Gerard (coord.), Los movimientos, sociales en el Caribe, Universidad Autónoma de Santo Domingo, 1987, pp. 253-276.

-Eusebio Pol, Noris, "Las ocupaciones de tierra en Ia República Dominicana", Ciencia y Sociedad, vol. VI, núm. 2, 1982, pp. 160-179.

-Fernández Reyes, Otto, Ideologías agrarias y lucha social en la República Dominicana (1961-1980), Consejo Latinoamericano de Ciencias Sociales, Buenos Aires, 1986.

-Fernández Rodríguez, Aura C., "Origen y evolución de la propiedad y de los terrenos comuneros en la República Dominicana", Eme-Eme: Estudios Dominicanos, vol. IX, núm. 51, 1980, pp. 4-45.

-Ferrán, Fernando I., Tabaco y sociedad: La organización del poder en el ecomercado de tabaco dominicano, Fondo para el Avance de las Ciencias Sociales y Centro de Investigación y Acción Social, Santo Domingo, 1976. 
-Gleijeses, Piero, La crisis dominicana, Fondo de Cultura Económica, México, 1985.

-González, Raymundo, "Campesinos y sociedad colonial en el siglo XVIII dominicano", Estudios Sociales, vol. XXV, núm. 87, 1992, pp. 15-28.

"Ideología del progreso y campesinado en el siglo XIX", Ecos: órgano del Instituto de Historia de la Universidad Autónoma de Santo Domingo, vol. I, núm. 2, 1993, pp. 25-43.

-Hoetink, H., El pueblo dominicano, 1850-1900: Apuntes para su sociología bistórica, Universidad Católica Madre y Maestra, Santiago, 3a ed., 1985.

-Inoa, Orlando, Estado y campesinos al inicio de la Era de Trujillo, Ediciones Librería La Trinitaria e Instituto del Libro, Santo Domingo, 1994.

-Knight, Melvin M., Los americanos en Santo Domingo: Estudios de imperialismo americano, Universidad de Santo Domingo, Ciudad Trujillo, 1939.

-Lluberes, Antonio, "La crisis del tabaco cibaeño, 1879-1930", en Tabaco, azúcar y minería, Banco de Desarrollo Interameérica, S.A. Museo Nacional de Historia y Geografia, Santo Domingo, 1984, pp. 3-22. el Cibao en la segunda mitad del siglo XIX", Eme-Eme: Estudios Dominicanos, vol. I, núm. 4, 1973, pp. 35-60.

- "Tabaco y catalanes en Santo Domingo durante el siglo XVII", EmeEme: Estudios Dominicanos, vol. v, núm. 28, 1977, pp. 13-26.

-Lowenthal, Abraham F., The dominican intervention, Harvard University Press, Cambridge, 1972.

-Lozano, Wilfredo, El reformismo dependiente (Estado, clases sociales y acumulación de capital en República Dominicana: 1966-78), Taller, Santo Domingo, 1985.

(comp.), La cuestión hattiamingo, 1992.
-Lundahl, Mats, Peasants and poverty: A study of Haiti, Croom Helm, Londres, 1979.

-Machín, Jorge, "Orígenes del campesinado dominicano durante la ocupación haitiana", Eme-Eme: Estudios Dominicanos, vol. I, núm. 4, 1973, pp. 19-34.

-Marínez, Pablo A, Agroindustria, Estado y clases sociales en la era de Trujillo (1935-1960), Fundación Cultural Dominicana, Santo Domingo, 1993.

, Democracia y procesos electorales en República Dominicana, Alfa \& Omega, Santo Domingo, 1994.

$\longrightarrow$ Resistencia campesina, imperialismo y reforma agraria en República Dominicana (1899-1978), CEPAE, Santo Domingo, 1984.

-Marte, Roberto, Estadísticas y documentos bistóricos sobre Santo Domingo (1805-1890), Museo Nacional de Historia y Geografía, Santo Domingo, 1984.

-Mateo, Andrés L., Mito y cultura en la Era de Trujillo, Ediciones Librería La Trinitaria, Santo Domingo, 1993.

-Moreno, Guillermo, "De la propiedad comunera a la propiedad privada moderna, 1844-1924", Eme-Eme: Estudios Dominicanos, vol. IX, núm. 51,1980 , pp. 47. 129.

-Moya Pons, Frank, La Dominación Hai tiana, 1822-1844, Universidad Católica Madre y Maestra, Santiago, 3a ed., 1978. , Empresarios en conflicto: Políticas de industrialización y sustitución de importaciones en la República Dominicana, Fondo para el Avance de las Ciencias Sociales, Santo Domingo, 1992.

, Las tres fronteras: Introducción a la frontera dominico-haitiana", en Lozano (comp.), La Cuestión Latina en Santo Domingo, Flacso, Santo Domingo, 1992, pp. 17-32.

-Nicholls, David, From Desaliness to Duvalier: race, colour and national independence in Haiti, Cambridge University Press, Cambridge, 1979. 
-Pierre-Charles, Gérard (coord.), Los movimientos sociales en el Caribe, Universidad Autónoma de Santo Domingo, Santo Domingo, 1987.

-Rodríguez Demorizi, Emilio (comp.), Papeles de Pedro Francisco Bono, Academia Dominicana de la Historia, Santo Domingo, 1964.

-San Miguel, Pedro L., Los campesinos del Cibao: economía de mercado y transformación agraria en la Republica Dominicana, 1880-1960, Editorial de la Universidad de Puerto Rico, San Juan, 1997.

do en la República Dominicana: el valle del Cibao, 1900-1960", Historia y Sociedad, vol. Iv, 1991, pp. 42-74.

, La isla imaginada: Historia, identidad y utopía en La Española, Editorial Isla Negra y Ediciones Librería La Trinitaria, San Juan y Santo Domingo, 1997.
, "Las luchas campesinas en la República Dominicana durante el siglo XX", ponencia en la IV Conferencia Anual de la Asociación Mexicana de Estudios del Caribe, Universidad de Quintana Roo, Chetumal, 25-27 de abril de 1997.

- "The making of a peasantry: dominican agrarian history from the 16 th to the 20th century", Punto y Coma: Revista Interdisciplinaria de la Universidad del Sagrado Corazón, vol. II, núms. 1-2, 1990, pp. 143-162.

, "Peasant resistance to State demands in the Cibao during the U.S. occupation", trad. Phillip Berryman, Latin American Perspectives, vol. 22, núm. 3, 1995, pp. 41-62.

-Scott, James C., The moral economy of the peasant: rebellion and subsistence in soutbeast Asia, Yale University Press, New Haven, 1976. 


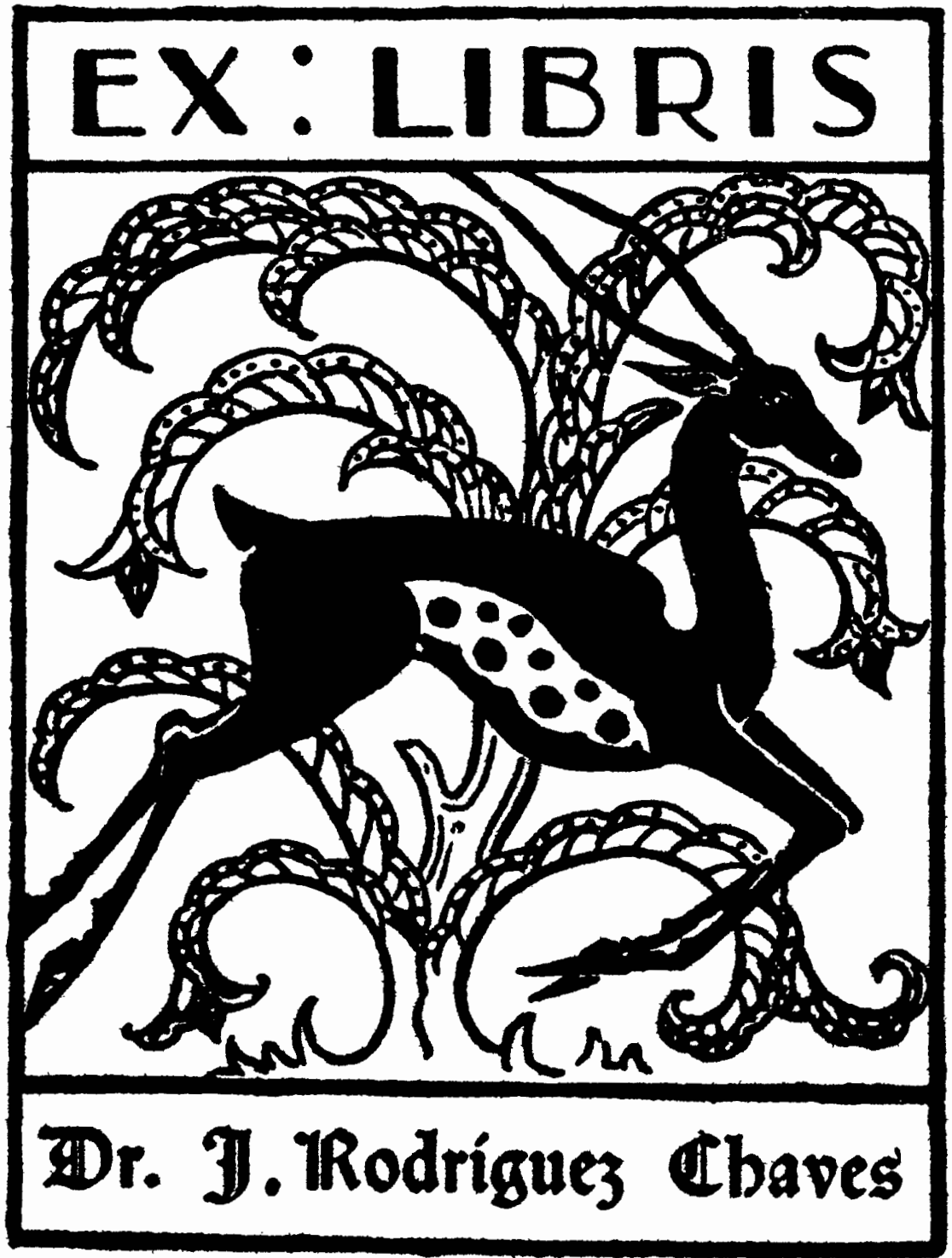

